\title{
The Prognostic value of the Fibrinogen to pre-albumin ratio in malignant tumors of the digestive system: a systematic review and meta-analysis
}

\author{
Baibei $\mathrm{Li}^{{ }^{\dagger \dagger}}$, Huachu Deng ${ }^{2 \dagger}$, Ziyan Zhou $^{3}$ and Bo Tang ${ }^{1^{*}}$ (1)
}

\begin{abstract}
Background: In recent years, the Fibrinogen to pre-albumin ratio (FPR) has been reported in many studies to be significantly associated with the prognosis of various cancers. This systematic review and meta-analysis aimed to investigate the prognostic value of FPR in malignant tumors of the digestive system based on available evidence.

Methods: The relevant articles published before July 1, 2021, were systematically retrieved from electronic databases to evaluate the effect of Fibrinogen to pre-albumin ratio (FPR) on the prognosis of patients with malignant digestive system tumors and calculate the hazard ratio (HR) and the corresponding 95\% confidence interval (Cl).

Result: Thirteen articles, all from China, including 15 cohort studies and a total of 5116 cases, were included in this study. A high FPR was associated with poor overall survival $(H R=1.88,95 \% \mathrm{Cl} 1.53-2.32, \mathrm{P}<0.001)$, recurrence-free survival $(H R=2.29,95 \% \mathrm{Cl} 1.91-2.76, \mathrm{P}<0.001)$, progression-free survival $(\mathrm{HR}=1.96,95 \% \mathrm{Cl}: 1.33-2.90, \mathrm{P}=0.001)$, complications ( $H R=1.78,95 \% \mathrm{Cl}: 1.06-3.00, P=0.029)$, disease-free survival $(H R=1.46,95 \% \mathrm{Cl}: 1.08-1.97, \mathrm{P}=0.013)$ was significantly associated with cancer-specific survival $(H R=1.44,95 \% \mathrm{Cl}: 1.15-1.79, \mathrm{P}=0.001)$. Even though intergroup differences were present, FPR was strongly associated with overall and relapse-free survival, and sensitivity analysis suggested that our results were stable.
\end{abstract}

Conclusion: FPR can be used as a valuable indicator to predict the prognosis of patients with malignant digestive system tumors.

Keywords: Fibrinogen to pre-albumin ratio, Prognosis, Digestive cancers

\section{Introduction}

Malignant tumors of the digestive system are among the most common malignancies globally, including colorectal carcinoma, carcinoma of the stomach, hepatic carcinoma, and esophageal carcinoma [1].Most patients

*Correspondence: dr_sntangbo@163.com

${ }^{\dagger}$ Baibei Li and Huachu Deng contributed equally to this work

${ }^{1}$ Department of Hepatobiliary Surgery, The First Affiliated Hospital

of Guangxi Medical University, No 6 Shuangyong Road, Nanning 530021, Guangxi, People's Republic of China

Full list of author information is available at the end of the article are unfortunately diagnosed at advanced cancer stages. According to the clinical staging, early cases of gastrointestinal cancers are usually treated by surgical resection and postoperative adjuvant therapy. For advanced cancers, chemotherapy and radiotherapy are the mainstays of oncologic therapy and can only modestly prolong the survival of patients. Due to intratumoral heterogeneity, malignant tumors are often resistant to chemotherapeutic drugs, leading to disease recurrence and a poor overall patient prognosis. Few oncologic treatment options are available in advanced diseases; accordingly, it is essential original author(s) and the source, provide a link to the Creative Commons licence, and indicate if changes were made. The images or other third party material in this article are included in the article's Creative Commons licence, unless indicated otherwise in a credit line to the material. If material is not included in the article's Creative Commons licence and your intended use is not permitted by statutory regulation or exceeds the permitted use, you will need to obtain permission directly from the copyright holder. To view a copy of this licence, visit http://creativecommons.org/licenses/by/4.0/. The Creative Commons Public Domain Dedication waiver (http://creativecommons.org/publicdomain/zero/1.0/) applies to the data made available in this article, unless otherwise stated in a credit line to the data. 
to explore new biomarkers such as the Fibrinogen to prealbumin ratio (FPR) to help clinicians during prognostic evaluation and assist in decision making.

Fibrinogen is a $340 \mathrm{KDa}$ hepatocyte-produced glycoprotein that can be converted to fibrin by activated thrombin. It modulates the coagulation and thrombosis process and plays an important role in hemostasis, cell attachment, and systemic inflammatory reactions [2].High Fibrinogen is an important risk factor for various thrombotic diseases and is also considered a marker of blood hypercoagulability in clinical practice, which is closely related to the occurrence and prognosis of various cardiovascular diseases [3]. Fibrinogen is also acknowledged as an acute-phase protein produced by the liver and is significantly elevated during an infection or inflammatory disease. Thus, it can also be used as a marker to mirror the inflammation level in an organism. Interestingly, malignant tumor cells can partially express Fibrinogen [4].Fibrinogen has also been associated with vascular endothelial cell growth factor (VEGF) and fibroblast growth factor 2 (FGF-2) and can promote tumor cell adhesion, proliferation and migration [5]. Elevated serum fibrinogen levels are usually associated with poor prognosis of human cancers [6, 7]. Pre-albumin, produced primarily in the liver, is a transportation protein found primarily in the blood. Its main functions are to bind and transport thyroid hormones and vitamin A [8]. Furthermore, serum pre-albumin is an important biomarker for assessing the nutritional status of cancer patients [9]. Reduced pre-albumin levels have also been documented in cancer patients and are associated with a poor prognosis.

Even though pre-albumin and Fibrinogen are all widely acknowledged to be associated with tumor prognosis, the Fibrinogen to pre-albumin ratio (FPR) has rarely been reported to evaluate the prognosis of patients with digestive tumors. At present, only one meta-analysis mentioned the correlation between FPR and OS of cancer patients, which proved that high FPR was associated with poor OS in cancer patients, but there was no independent report on the relationship between FPR and malignant digestive system tumors, and there was no report on the relationship between FPR and recurrence-free survival [10]. Therefore, the aim of this study was to conduct a systematic review and meta-analysis of available evidence to assess the prognostic value of FPR in malignant digestive system tumors.

\section{Methods}

\section{Search strategy and selection criteria}

This systematic review followed the Preferred Reporting Items for Systematic Reviews and Meta-Analyses (PRISMA) guidelines [11].In this regard, the databases of the Cochrane Library, Embase, PubMed, Google Scholar, Baidu Scholar, CNKI and VIP were searched for relevant articles published not later than July 1, 2021. In addition, we also mine studies that meet the inclusion criteria from TCGA and GEO databases. The complete search strategy is as follows: (" $f$ fibrinogen to pre-albumin ratio" or "fibrinogen" or "pre-albumin" or "FPR") AND ("colorectal cancer" or "gastric cancer" or "liver cancer" or "esophageal cancer" or "cancer" or "carcinoma")). Wildcards and Boolean operators were used to perform a comprehensive search.

The eligibility criteria were defined according to the Population, Intervention, Comparison, Outcome and Study Design (PICOS) strategy. Patients with digestive tumors were identified as "Population" at the time of retrieval; high FPR and low FPR represented "Intervention" and "Comparison" respectively; overall survival (OS), recurrence-free survival (RFS), cancer-specific survival (CSS), disease-free survival (DFS), progression-free survival (PFS) and complication were the "Outcome" of this study; "Study design" choice was retrospective and prospective research, and case reports, letters, reviews, editorials and comments were ruled out. If there were duplicates, the most recently published record would be included.

\section{Data extraction}

Duplicates were removed using EndNote (version X8), and eligible studies were entered into a database built by EpiData (version 3.0). Two reviewers independently extracted the required data from the included studies using a special Excel spreadsheet, including author name, publication date, study location, study design (prospective or retrospective research), type of patient, sample size, age composition, gender, primary treatment (surgical and others), cutoff value, methods for choosing FPR cutoff value, outcome, data source (crude data or fitted curve) and duration of follow-up. Outcome indicators included primary (OS and RFS) and secondary outcome indicators (CSS, DFS, PFS and complications). The inclusion of relevant literature and the processing of all data were performed by two independent reviewers (BL and HD). Points of disagreement were reconciled by a discussion with a third reviewer.

\section{Statistical analysis}

All statistical analyses were performed using STATA (version 12). The extracted data was used for calculating hazard ratios (HRs) and 95\% CI and used to evaluate the prognostic value of FPR in digestive system malignant tumors. $\mathrm{I}^{2}$ statistics were used to quantify the heterogeneity between the included studies and calculated the proportion of variation due to heterogeneity rather 
than due to chance; $\mathrm{I}^{2}$ values ranged from 0 to $100 \%$, with higher values indicating greater heterogeneity. If $\mathrm{I}^{2}>50 \%$, the random-effects model was chosen; otherwise, the fixed-effects model was selected. Moreover, subgroup analysis was conducted to explore whether publishing time, methods for choosing FPR cutoff value (ROC or $\mathrm{X}$-tile), cutoff value, types of cancer (colorectal cancer, gallbladder cancer, gastric cancer, hepatocellular cancer or esophageal squamous cell cancer), study design (prospective or retrospective), treatment option (surgical resection or others) and sample capacity had any influence on the results. In addition, sensitivity analysis was used to evaluate the reliability and stability of the results, and Begger's and Egger's tests were used to test whether there was a potential publication bias in the study. $\mathrm{P}>0.05$ is considered to be free of publication bias, otherwise the trim-and-fill method will be used for reevaluation. All tests were bilateral tests, and $\mathrm{P}<0.05$ was considered to be statistically significant.

\section{Results}

\section{Study characteristics}

The flowchart documenting retrieval of studies from electronic databases is illustrated in Fig. 1. A total of 13 relevant articles were included in this study, including 15 cohort studies and 5116 patients [12-24]. Unfortunately, we have not found any studies that meet the inclusion criteria from TCGA and GEO databases. Among the included articles, all the studies were conducted in China, 7 were retrospective analyses, and 8 were prospective analyses, the year of publication was from 2017 to 2021 ,the sample size was $42-1014$, and the FPR cutoff value was $0.014-31.84$.The meta-analysis involved a variety of malignant digestive tumors, including colorectal carcinoma (CRC), carcinoma of the stomach (GC), carcinoma of gall bladder (GBC), hepatic carcinoma (HCC), esophageal squamous cell carcinoma (ESCC) and colorectal mucinous adenocarcinoma (CMA). In addition, ten studies reported OS, four studies reported RFS, two studies reported PFS, and one study reported on postoperative complications, CSS, and DFS. Baseline information for each study is shown in Table 1.

\section{FPR and overall survival}

A total of 3313 patients included in 10 cohort studies were analyzed to assess the prognostic significance of FPR levels on OS in malignant digestive tumors. The combined forest plot showed that a high FPR was associated with poor OS (HR $=1.88$, 95\%CI $1.53-$ 2.32, $\mathrm{p}<0.001)$. Due to the significant heterogeneity $\left(\mathrm{I}^{2}=50.8 \%, \mathrm{p}=0.032\right)$, we used the random effect model (Fig. 2) and performed a hierarchical subgroup analysis by time of publishing, sample size, cutoff value, methods for choosing FPR cutoff value, cancer site, treatment option and designed type (Table 2). High FPR was significantly associated with poor OS, although intergroup differences were present. Moreover, the heterogeneity in some subgroups was eliminated when we stratified according to factors, including "ROC", "sample capacity $\geq 330$ ", "retrospective" and "other treatment options".

\section{Sensitivity analysis and Publication bias for OS}

Sensitivity analysis was used to assess the influence of individual studies on the aggregate result, with one inclusion study deleted at a time. The results showed that all of the included studies were close to the centerline, and omitting any of the studies did not change the significant effect of FPR on OS, demonstrating that our results were robust and reliable (Fig. 3) In the present study, Begg's test $(p=0.004)$ and Egger's test $(p=0.001)$ were used to investigate publication bias in the included literature, and the funnel plots were asymmetric $(\mathrm{p}<0.05)$, suggesting that there might be publication bias in this study (Fig. 4a, b). Then, we use the trim-and-fill method to identify and correct possible publication biases. A symmetrical funnel diagram was obtained by adding four studies, nonetheless, the corrected HR did not change significantly $(\mathrm{HR}=1.572,95 \% \mathrm{CI} 1.242-1.989, \mathrm{p}<0.001)$, suggesting that our conclusion is stable (Fig. 4c).

\section{FPR and recurrence-free survival}

Four studies involving 1,920 patients reported the association between FPR and postoperative recurrence-free survival in patients with malignant tumors of the digestive system. The comprehensive results showed that a high FPR was related to poor RFS in patients with malignant digestive system tumors $(\mathrm{HR}=2.29,95 \%$ CI 1.91-2.76, $\mathrm{p}<0.001)$. In the absence of heterogeneity $\left(\mathrm{I}^{2}=35.3 \%, \mathrm{P}=0.201\right)$, we used a fixed-effect model (Fig. 5). In addition, we performed subgroup analyses based on publication time, sample size, study type, and cancer type. The results showed that FPR was an independent prognostic factor affecting RFS in each subgroup (Table 3) After deleting each study, we recalculated the merger of $\mathrm{HR}$ and $95 \% \mathrm{CI}$ for sensitivity analysis (Fig. 6). The final results suggested that the deletion of any study cohort did not affect the RFS. In other words, the combined results of our meta-analysis were stable. In addition, both Begg's test $(\mathrm{p}=1.000)$ and Egger's test $(\mathrm{p}=0.522)$ indicated no potential publication bias was present in the meta-analysis of RFS (Fig. 7a, b).

\section{Association between FPR and other outcomes}

We also investigated the effects of FPR on the prognosis of complications, PFS, DFS, and CSS in patients with malignant tumors of the digestive system. The prognostic 


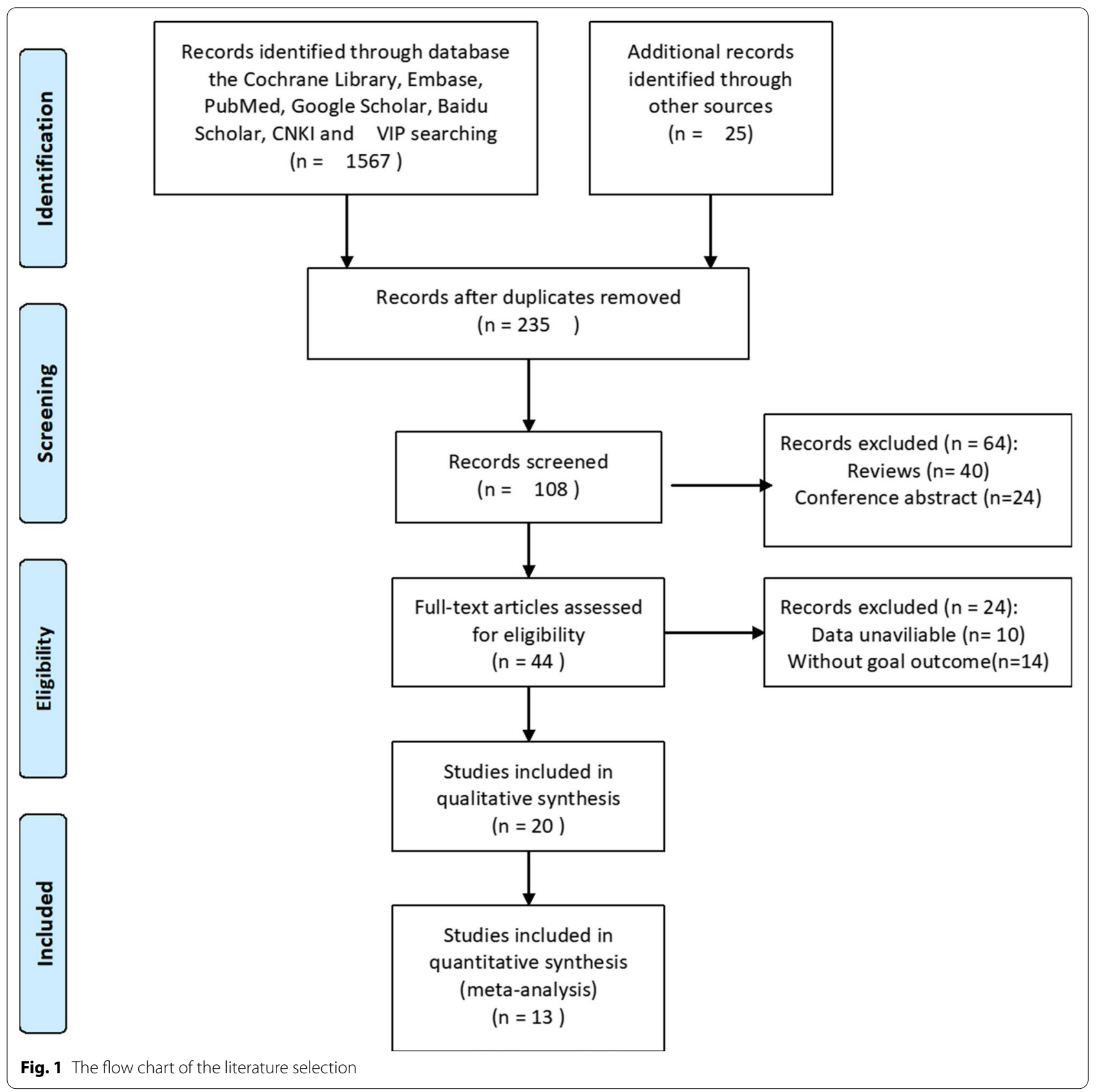

value of FPR for progression-free survival was reported in two cohort studies, including 113 patients (Fig. 8A), using a fixed-effect model due to the absence of heterogeneity. $\left(\mathrm{I}^{2}=0.0 \%, \mathrm{p}=0.511\right)$ The combined results showed that PFS was significantly shorter in patients with high FPR than in patients with low FPR $(\mathrm{HR}=1.96,95 \% \mathrm{CI}$ : $1.33-2.90, \mathrm{p}=0.001)$. A study involving 584 patients showed that high FPR was an independent risk factor for complications and disease-free survival $(\mathrm{HR}=1.78$, 95\%CI $1.06-3.00, \mathrm{p}=0.029$ and $\mathrm{HR}=1.46,95 \% \mathrm{CI} 1.08$ 1.97, $\mathrm{p}=0.013$ ) (Fig. 8B, C). Similarly, a study involving 372 patients showed that FPR was an independent predictor of cancer-specific survival in patients with malignant tumors of the digestive system $(\mathrm{HR}=1.44,95 \% \mathrm{CI}$ $1.15-1.79, \mathrm{p}=0.001$ ) (Fig. 8D). 


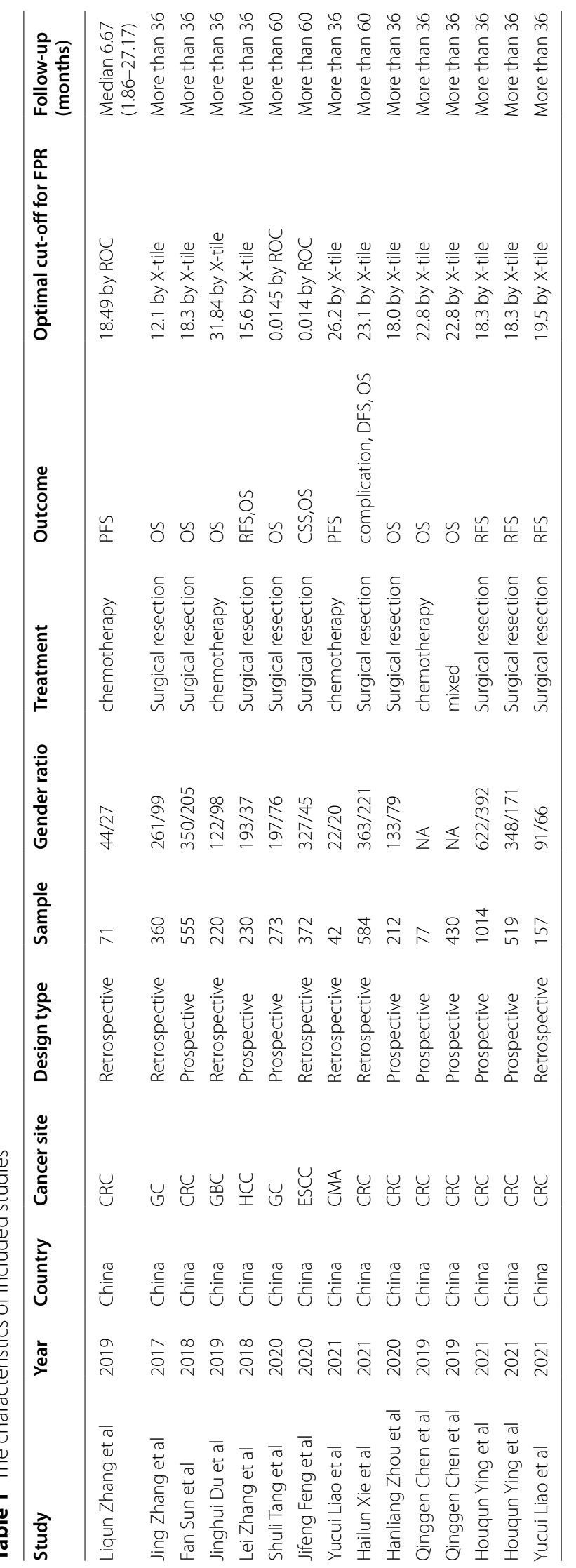




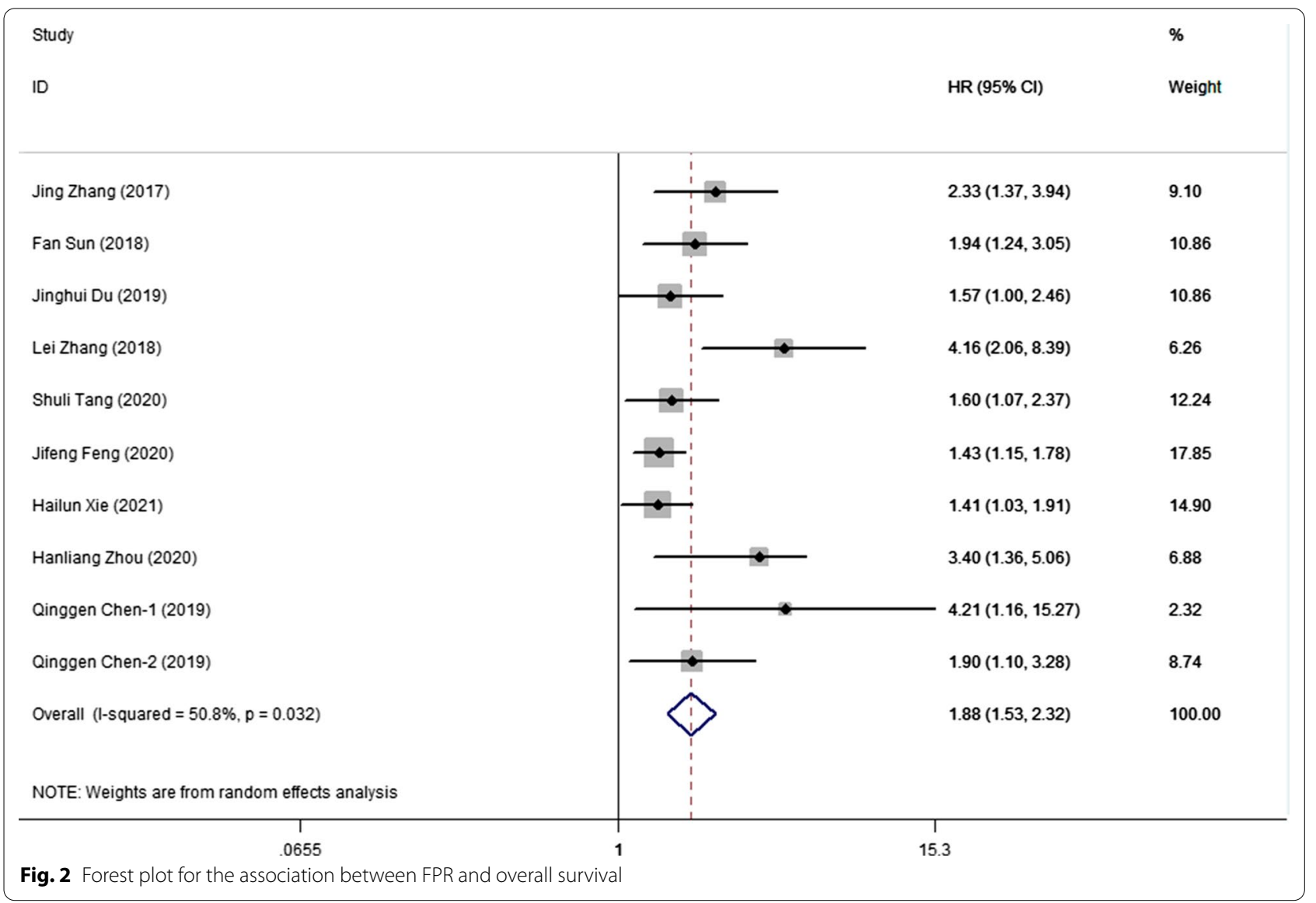

\section{Discussion}

Pre-albumin, also known as transthyretin, is synthesized by the liver and regulates vitamin A and thyroxine synthesis and transportation [8].Given that the half-life of pre-albumin is only about two days, it can reflect minor changes caused by malnutrition and liver insufficiency in a short period [12, 25].Fibrinogen has been reported to be involved in the formation of the inflammatory microenvironment, inflammatory level, angiogenesis, malignant tumor cell proliferation, invasion, and metastasis as an important inflammatory factor [26]. Available metaanalyses suggest that fibrinogen is a prognostic factor for acute myeloid leukemia, venous thromboembolism, cardiovascular disease, and solid tumors [27-30].

Mounting studies have shown that pre-albumin(PA) and fibrinogen regulate the occurrence and development of various tumors, and their levels in peripheral blood are closely related to the patient's survival and sensitivity to therapy [31, 32].As a novel, effective, economical and practical biomarker, the fibrinogen to pre-albumin ratio (FPR) is not only gradually used to evaluate the prognosis of digestive system tumors such as colorectal cancer [20], hepatocellular carcinoma [16] and gastric cancer [13], but also as an index to predict the prognosis of lung [33] and bladder cancer [34]. A study of patients with NSCLC reported that FPR is an independent factor affecting OS in patients with advanced NSCLC [33]. However, most studies on FPR have explored the relationship between FPR and malignant tumors of the digestive system. In other words, PFR may be an important indicator in the field of malignant digestive system tumors research. A study of 230 patients showed that FPR was superior to other biomarkers to independently predict survival of HCC patients and could identify which patients would benefit from adjuvant chemotherapy [16]. Ying et al. [23] suggested that FPR was more effective than other inflammatory markers in predicting recurrence of CRC in stage II-III surgical patients.

Single markers of fibrinogen and pre-albumin are limited and unstable in predicting the prognosis of digestive system tumors [13]. Hailun Xie et al. [20] found that pre-albumin and fibrinogen themselves do not affect postoperative complications and long-term prognosis of patients with colorectal cancer, while FPR can be used as a predictor of postoperative complications and long-term prognosis of colorectal cancer. FPR can not only reflect 
Table 2 Subgroup Meta-analysis of FPR and OS

\begin{tabular}{|c|c|c|c|c|c|c|}
\hline \multirow[t]{2}{*}{ Subgroup } & \multirow[t]{2}{*}{ No. of cohorts } & \multirow[t]{2}{*}{ No. of patients } & \multirow[t]{2}{*}{ Pooled HR $(95 \% \mathrm{Cl})$} & \multirow[t]{2}{*}{$\mathbf{P}$} & \multicolumn{2}{|c|}{ Heterogeneity } \\
\hline & & & & & $I^{2}(\%)$ & $P_{h}$ \\
\hline Altogether & 10 & 3313 & $1.88(1.53,2.32)$ & $<0.001$ & 50.8 & 0.032 \\
\hline \multicolumn{7}{|l|}{ Publishing time } \\
\hline$<2020$ & 6 & 1872 & $2.10(1.67,2.64)$ & $<0.001$ & 25.9 & 0.24 \\
\hline$\geq 2020$ & 4 & 1441 & $1.61(1.25,2.09)$ & $<0.001$ & 53.0 & 0.095 \\
\hline \multicolumn{7}{|l|}{ Sample capacity } \\
\hline$<330$ & 5 & 1012 & $2.39(1.55,3.70)$ & $<0.001$ & 60.9 & 0.037 \\
\hline$\geq 330$ & 5 & 2301 & $1.57(1.35,1.83)$ & $<0.001$ & 14.3 & 0.323 \\
\hline \multicolumn{7}{|c|}{ Methods for choosing FPR cut-off value } \\
\hline $\mathrm{ROC}$ & 2 & 645 & $1.47(1.21,1.78)$ & $<0.001$ & 0.0 & 0.635 \\
\hline X-tile & 8 & 2668 & $2.11(1.61,2.77)$ & $<0.001$ & 50.8 & 0.047 \\
\hline \multicolumn{7}{|l|}{ Cut-off value } \\
\hline$<18$ & 4 & 1235 & $1.96(1.34,2.89)$ & 0.001 & 69.8 & 0.019 \\
\hline$\geq 18$ & 6 & 2078 & $1.75(1.44,2.12)$ & $<0.001$ & 39.0 & 0.146 \\
\hline \multicolumn{7}{|l|}{ Study designed type } \\
\hline Retrospective & 4 & 1536 & $1.50(1.28,1.76)$ & $<0.001$ & 2.3 & 0.381 \\
\hline Prospective & 6 & 1777 & $2.32(1.68,3.19)$ & $<0.001$ & 43.6 & 0.115 \\
\hline \multicolumn{7}{|l|}{ Treatment option } \\
\hline Surgical resection & 7 & 2586 & $1.92(1.48,2.48)$ & $<0.001$ & 62.8 & 0.013 \\
\hline Others & 3 & 727 & $1.80(1.29,2.52)$ & 0.001 & 3.0 & 0.357 \\
\hline \multicolumn{7}{|l|}{ Cancer site } \\
\hline GC & 2 & 633 & $1.83(1.33,2.51)$ & $<0.001$ & 20.8 & 0.261 \\
\hline CRC & 5 & 1858 & $2.00(1.42,2.81)$ & $<0.001$ & 49.5 & 0.095 \\
\hline GBC & 1 & 220 & $1.57(1.00,2.46)$ & 0.049 & NA & NA \\
\hline $\mathrm{HCC}$ & 1 & 230 & $4.16(2.06,8.39)$ & $<0.001$ & NA & NA \\
\hline ESCC & 1 & 372 & $1.43(1.15,1.78)$ & 0.002 & NA & NA \\
\hline
\end{tabular}

the level of inflammation in patients, but also indicate the nutritional status of patients [35].Patients with high FPR have reduced nutritional levels and a reduced burden of cancer-related inflammation, which can lead to impaired immune detection and recovery [36]. FPR balances the effects of inflammation and nutrition, and is a comprehensive indicator that reflects a patient's biological status more comprehensively.

The reason why FPR is related to the prognosis of digestive tract tumors is not clear. However, there are several possible mechanisms. Fibrinogen and pre-albumin are liver acute phase positive and negative proteins, respectively [37]. Kris A et al. [38] reported that fibrinogen plays an important role in the occurrence and development of inflammation-dependent cancer. In the process of cancer development, microvascular destruction caused by inflammation results in the accumulation of fibrinogen and other FDPS, which stimulates the secretion of more cytokines and chemokines and further promotes the invasion of cancer [39, 40]. Many studies have shown that fibrinogen increases the metastatic potential of tumor cells. Fibrinogen can act as a bridge between platelets and circulating tumor cells (CTCs), thus promoting platelet adhesion to CTCs [41]. In particular, thrombin can catalyze the conversion of fibrinogen in the circulatory system into a dense fibrin matrix, which then connects with platelets to form a stable skeleton and extracellular matrix around tumor cells to protect them from being killed by immune cells [42, 43]. In addition, fibrinogen can also directly bind to the intercellular adhesion molecule-1 (ICAM-1) of endothelial cells to promote tumor cell migration [44]. In addition, animal experiments showed that tumor cell metastasis was significantly inhibited in fibrinogen deficient mice [45]. Pre-albumin has a shorter half-life than albumin, is more susceptible to dramatic changes in liver function and responds more quickly to nutritional requirements [46]. It has been reported that IL-6 secreted by tumorrelated fibroblasts can inhibit pre-albumin and stimulate fibrinogen, resulting in the decrease of pre-albumin and the increase of fibrinogen [37]. In other words, the value of FPR also increases. People with high FPR cues have 


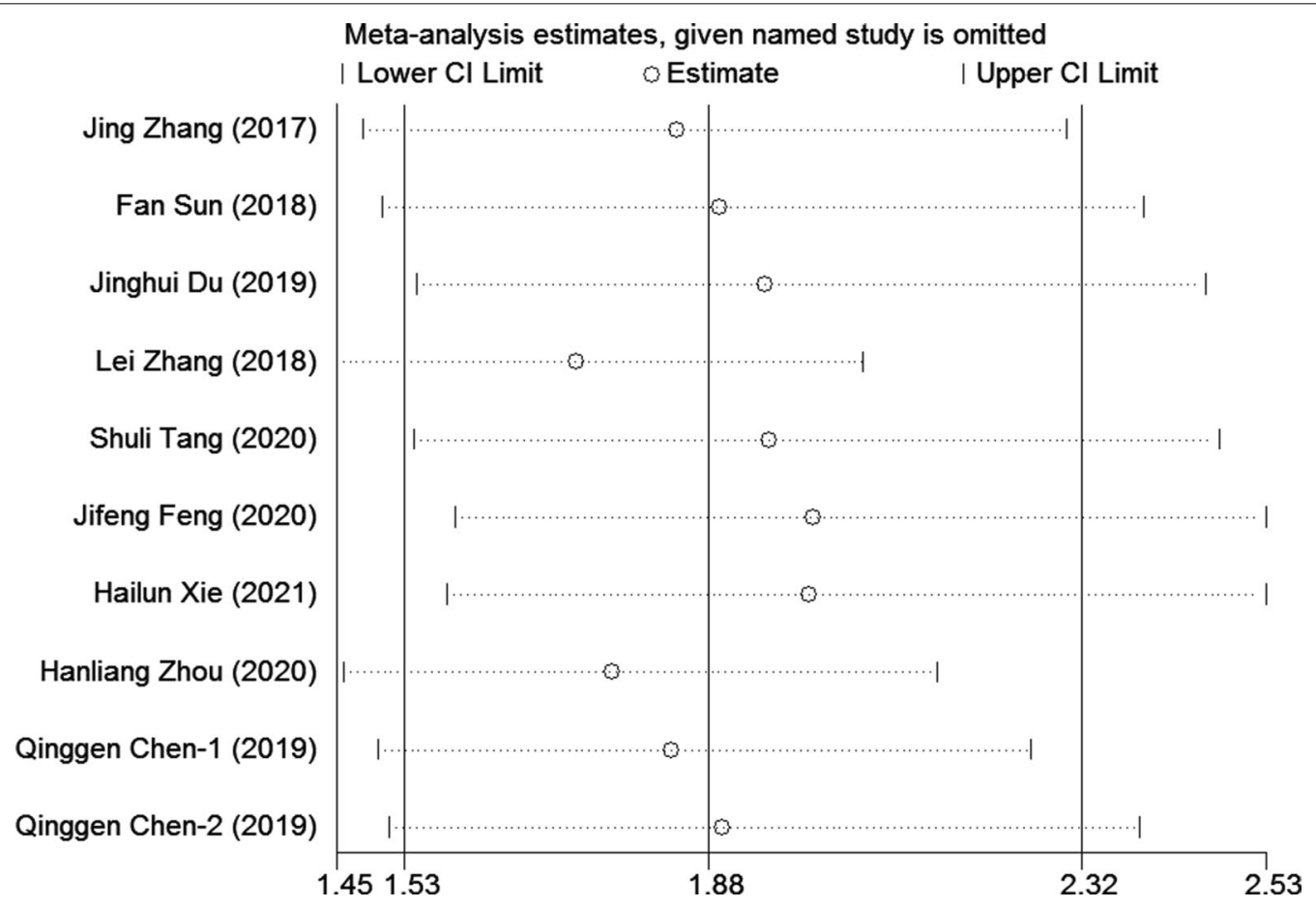

Fig. 3 Sensitivity analysis for the association between FPR and OS. OS: overall survival

malnutrition, impaired liver function, hypoproteinemia, and hypercoagulable state, which are usually clinical symptoms of patients with digestive tract tumors. Therefore, the study of FPR will reveal the relationship between cancer-related inflammation, disease and nutrition, indicating the progress of the disease.

Herein, we included 13 studies involving 5116 patients with malignant tumors of the digestive system. Existing evidence indicates that FPR is a sensitive indicator for predicting the prognosis of patients in this population, and patients with a high FPR exhibited worse OS than those with a low FPR. In the meantime, subgroup analysis was also conducted to explore the influence of various factors on our final findings. Although publication time, sample size, cutoff value, source of cutoff value, cancer site, treatment option and type of study varied in different groups, a high FPR was still significantly associated with poor prognosis. We further verified the stability of the meta-analysis by conducting sensitivity analysis and adjusting for censoring. In addition, we further discussed the relationship between FPR and recurrence-free survival in patients. The comprehensive results showed that FPR was an independent predictor of RFS in patients with malignant digestive system tumors. At the same time, subgroup analysis showed that although there were differences in publication time, sample size, research type and cancer system among different subgroups, high
FPR still correlated significantly with poor RFS. Sensitivity analysis indicated that our conclusions on RFS were robust, and the funnel chart exhibited no potential publication bias. In addition, we also discussed the relationship between FPR and other prognostic indicators of malignant tumors of the digestive system. A high FPR was associated with adverse clinical outcomes in terms of CSS, DFS, PFS, and complications. In all events, FPR can be considered an important and practical clinical indicator to predict patient prognosis.

To the best of our knowledge, this is the first metaanalysis to comprehensively examine the prognostic value of FPR in patients with malignant tumors of the digestive system. Based on the available evidence, FPR was associated with significant outcomes (OS and RFS) in the present study and correlated with adverse clinical outcome indicators (complication, DFS, PFS and CSS). We also performed a rigorous subgroup analysis and sensitivity analysis to further demonstrate the prognostic significance of FPR in these patients. In addition, the cut-off values of FPR in most of the included studies are mainly concentrated in the range of 18 to 23.1, which provides a certain reference value for clinically determining the critical value of FPR.

However, it should be noted that there are some limitations in our meta-analysis. First of all, all the included studies were conducted in China; accordingly, 


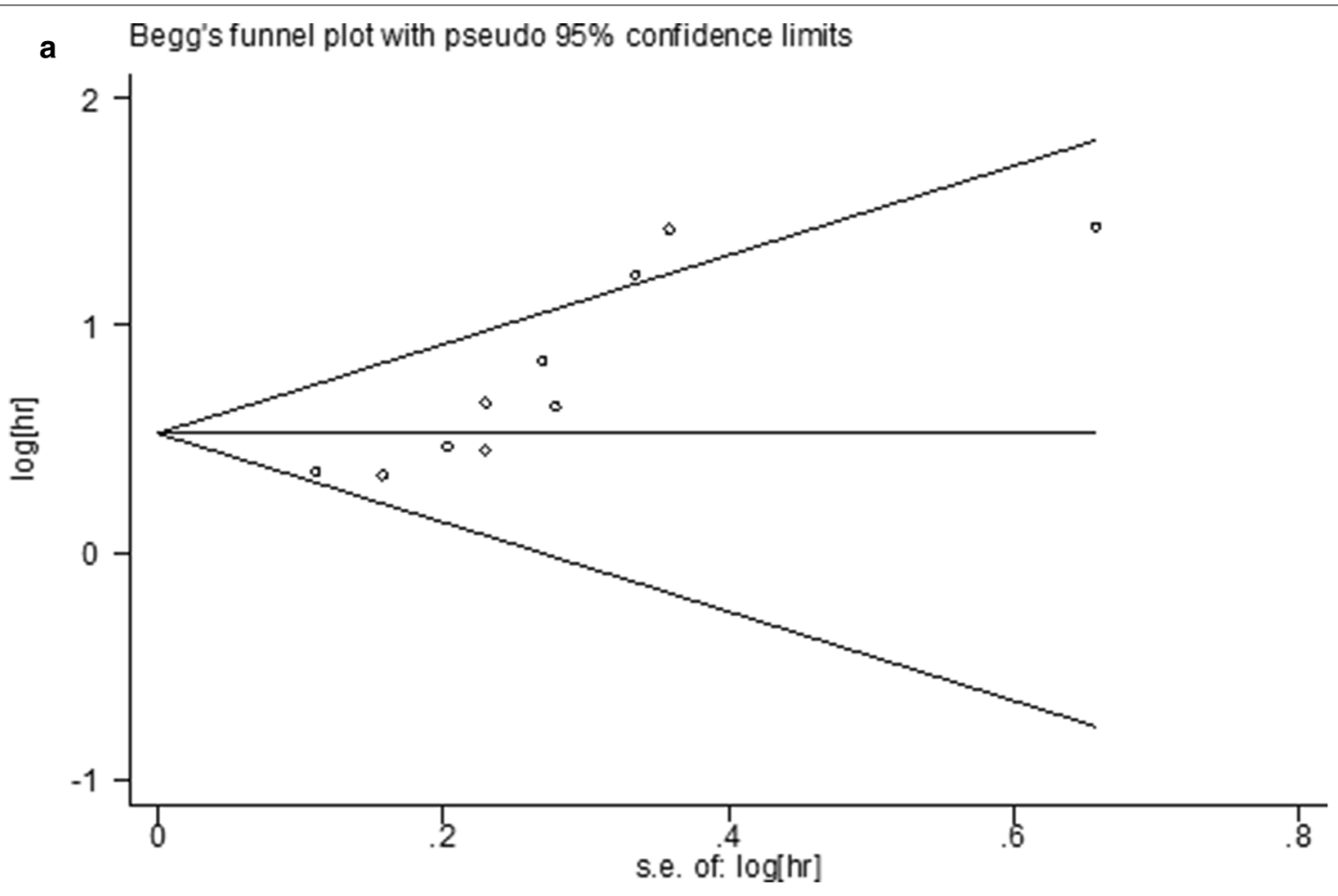

b Egger's publication bias plot

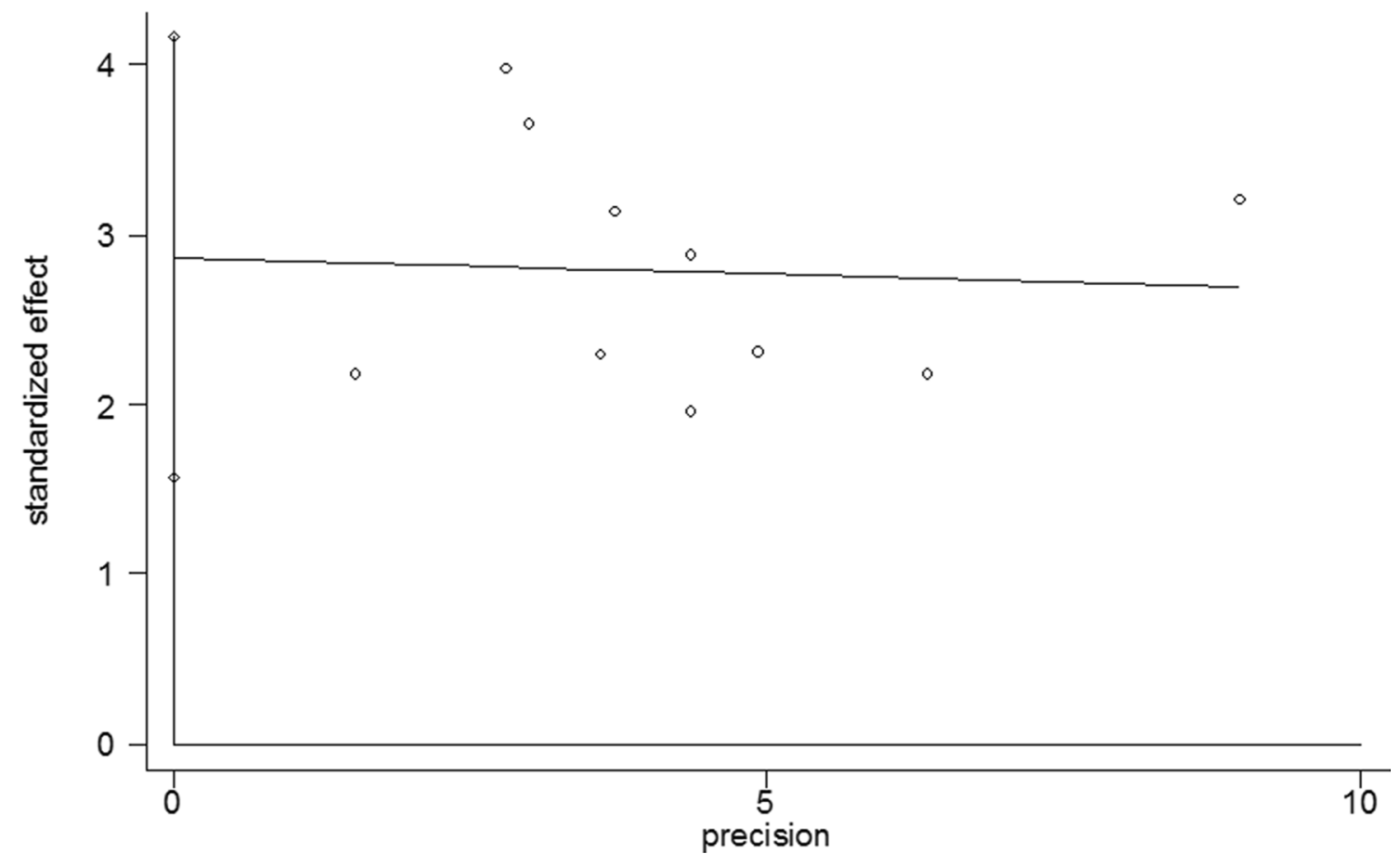

Fig. 4 Plots for publication bias test in meta-analysis for overall survival. a Begg's funnel plot; b Egger's publication bias plot; c The trim-and-fill methods; 


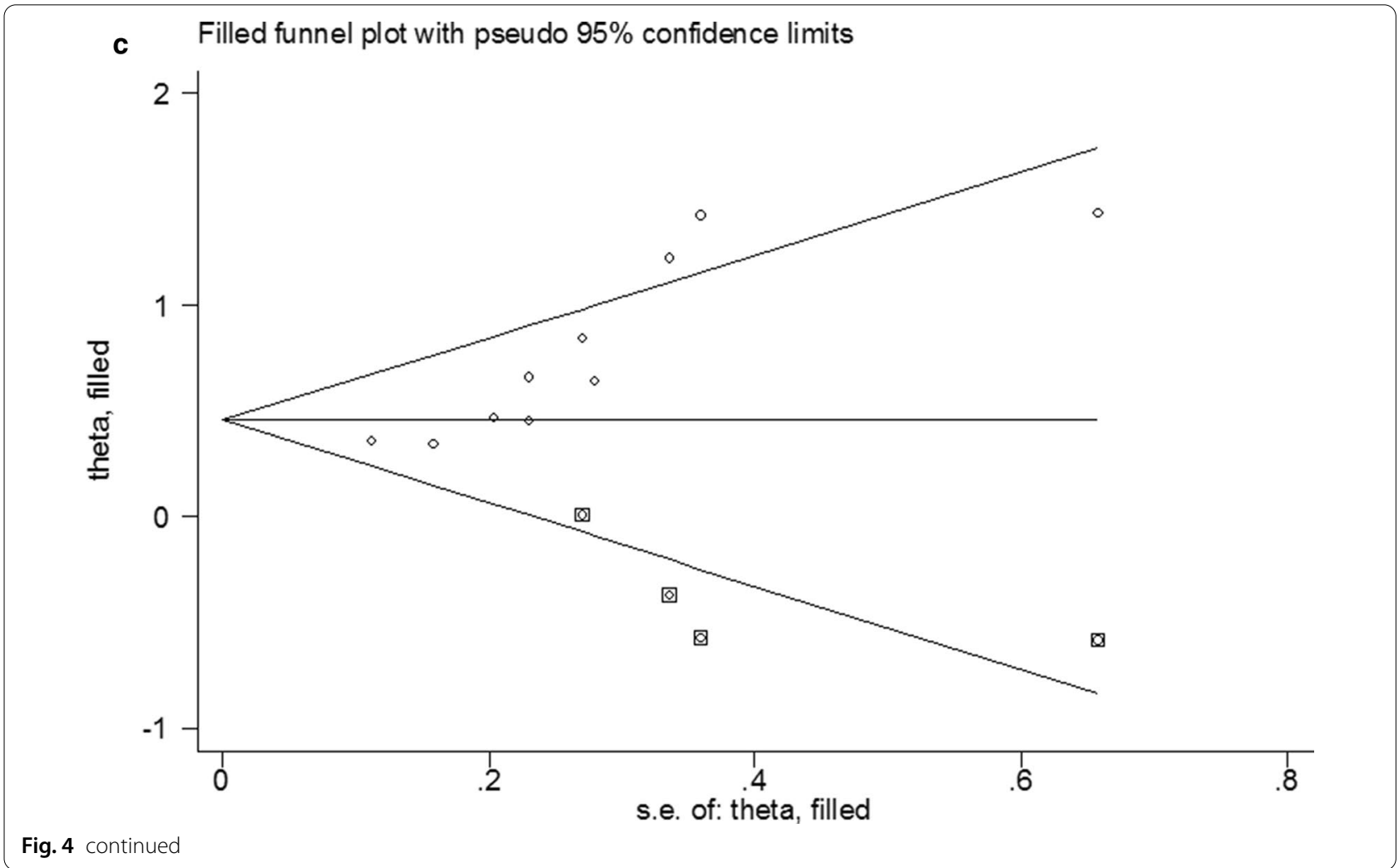

Study

ID

Lei Zhang (2018)

Houqun Ying-1 (2021)

Houqun Ying-2 (2021)

Yucui Liao (2021)

Overall (I-squared $=35.3 \%, p=0.201$ )



Fig. 5 Forest plot for the association between FPR and recurrence-free survival
$\mathrm{HR}(95 \% \mathrm{Cl}) \quad$ Weight

$\begin{array}{ll}1.76(1.04,2.99) & 12.27 \\ 2.77(2.14,3.58) & 51.38 \\ 1.85(1.32,2.58) & 30.31 \\ 2.36(1.12,4.99) & 6.04 \\ 2.29(1.91,2.76) & 100.00\end{array}$

4.99 
Table 3 Subgroup Meta-analysis of FPR and RFS

\begin{tabular}{|c|c|c|c|c|c|c|}
\hline \multirow[t]{2}{*}{ Subgroup } & \multirow[t]{2}{*}{ No.of cohorts } & \multirow[t]{2}{*}{ No. of patients } & \multirow[t]{2}{*}{ Pooled HR $(95 \% \mathrm{Cl})$} & \multirow[t]{2}{*}{$\mathbf{P}$} & \multicolumn{2}{|c|}{ Heterogeneity } \\
\hline & & & & & $I^{2}(\%)$ & $P_{h}$ \\
\hline Altogether & 4 & 1920 & $2.29(1.91,2.76)$ & $<0.001$ & 35.3 & 0.201 \\
\hline \multicolumn{7}{|l|}{ Publishing time } \\
\hline$<2021$ & 1 & 230 & $1.77(1.04,2.99)$ & 0.034 & NA & NA \\
\hline$\geq 2021$ & 3 & 1690 & $2.32(1.73,3.11)$ & $<0.001$ & 43.6 & 0.170 \\
\hline \multicolumn{7}{|l|}{ Sample capacity } \\
\hline$<480$ & 2 & 387 & $1.94(1.26,2.99)$ & 0.002 & 0.0 & 0.534 \\
\hline$\geq 480$ & 2 & 1533 & $2.38(1.94,2.92)$ & $<0.001$ & 71.8 & 0.060 \\
\hline \multicolumn{7}{|c|}{ Study designed type } \\
\hline Retrospective & 1 & 157 & $2.36(1.12,4.99)$ & 0.025 & NA & NA \\
\hline Prospective & 3 & 1763 & $2.17(1.59,2.97)$ & $<0.001$ & 56.8 & 0.099 \\
\hline \multicolumn{7}{|l|}{ Cancer site } \\
\hline $\mathrm{HCC}$ & 1 & 230 & $1.77(1.04,2.99)$ & 0.034 & NA & NA \\
\hline CRC & 3 & 1690 & $2.32(1.73,3.11)$ & $<0.001$ & 43.6 & 0.170 \\
\hline
\end{tabular}

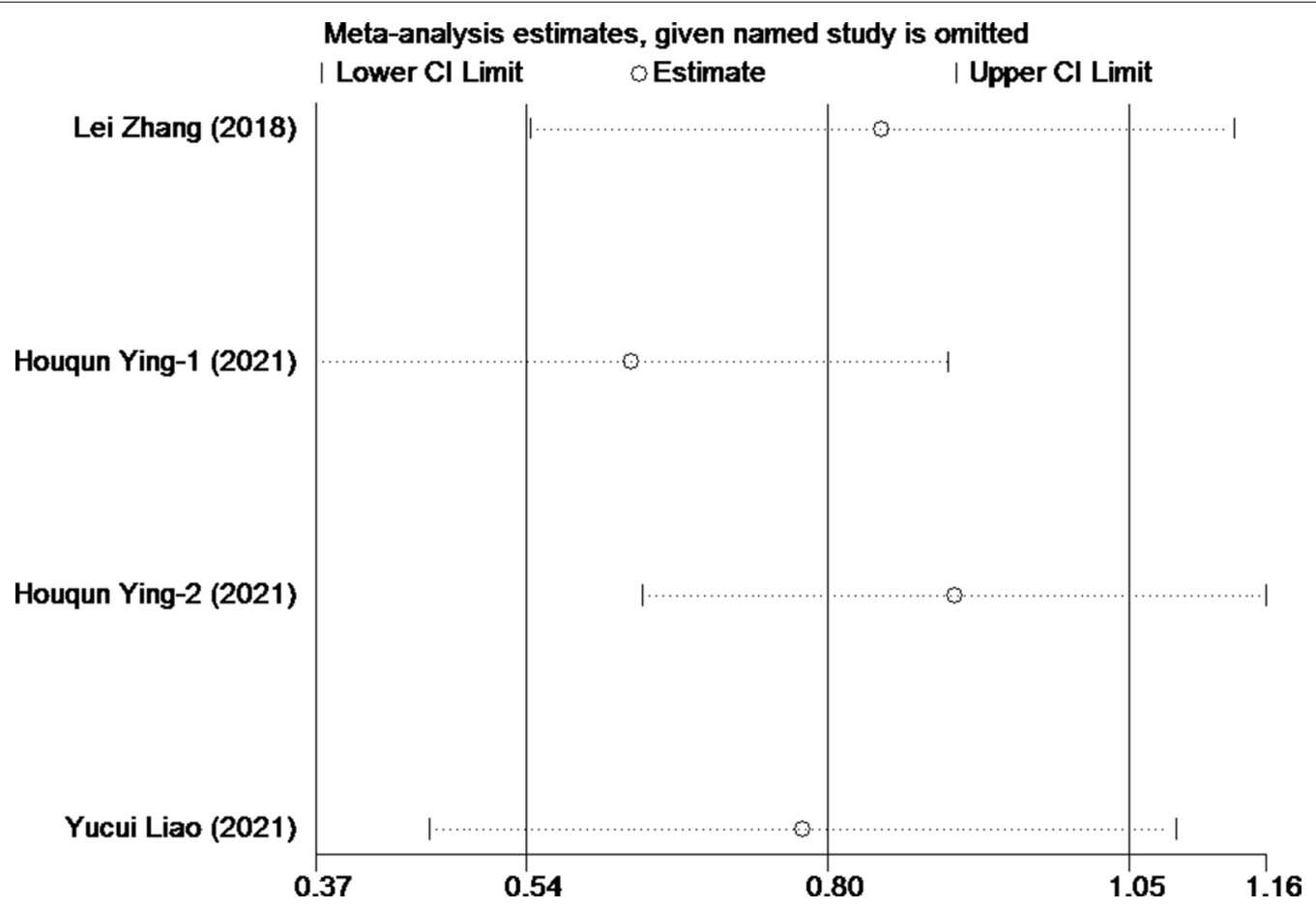

Fig. 6 Sensitivity analysis for the association between FPR and RFS. RFS: recurrence-free survival

the drawn conclusions mainly indicate that FPR has certain clinical value in the treatment of patients with malignant tumors of the digestive system in China; accordingly, more large scale studies worldwide are needed to provide sufficient evidence to substantiate the veracity of our findings. Moreover, significant heterogeneity was present in our meta-analysis, which may have been caused by the small number of included studies and samples. Finally, due to the limited number of included studies, the cutoff value of FPR in CSS, DFS, PFS and complications remains to be explored. 


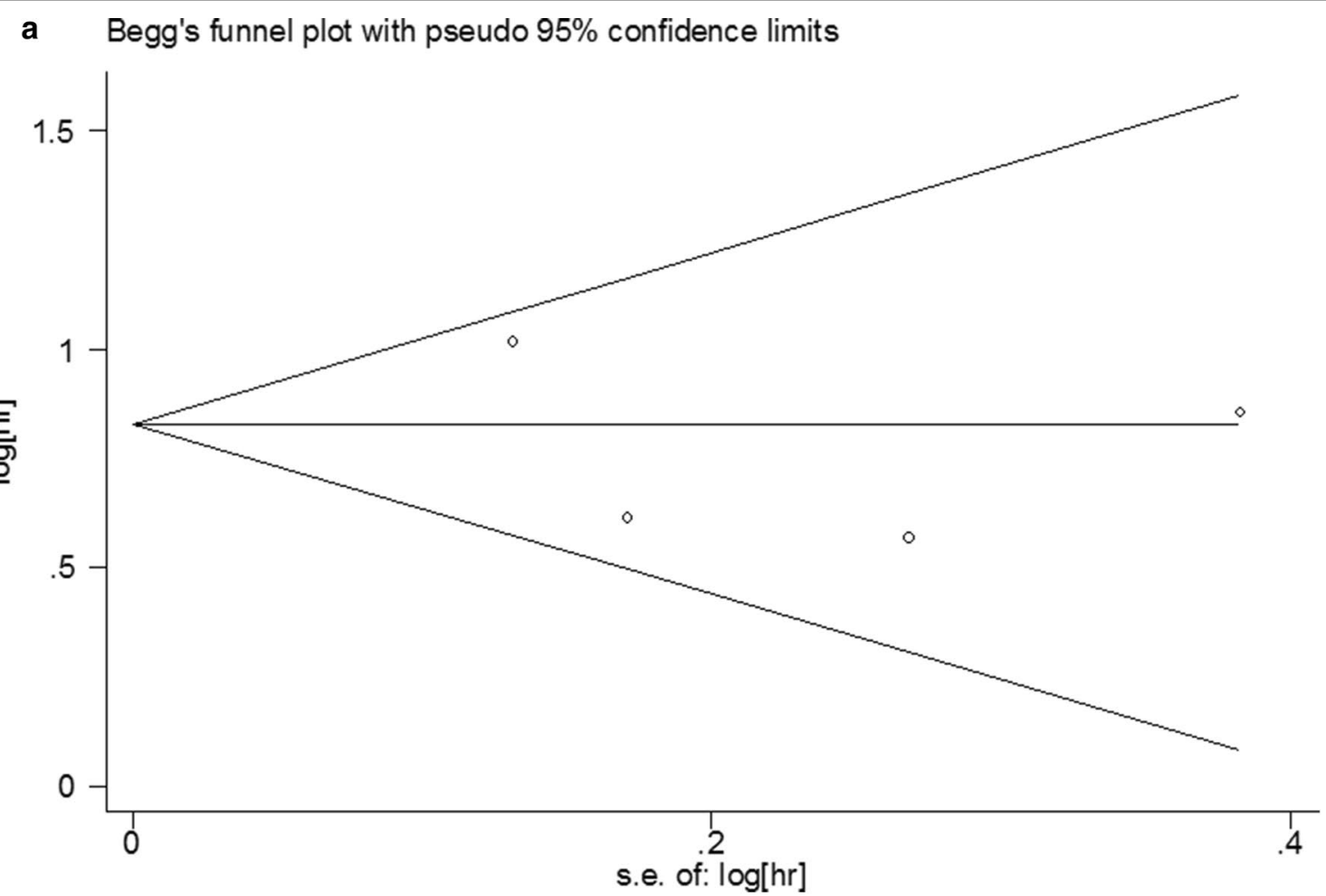

b Egger's publication bias plot

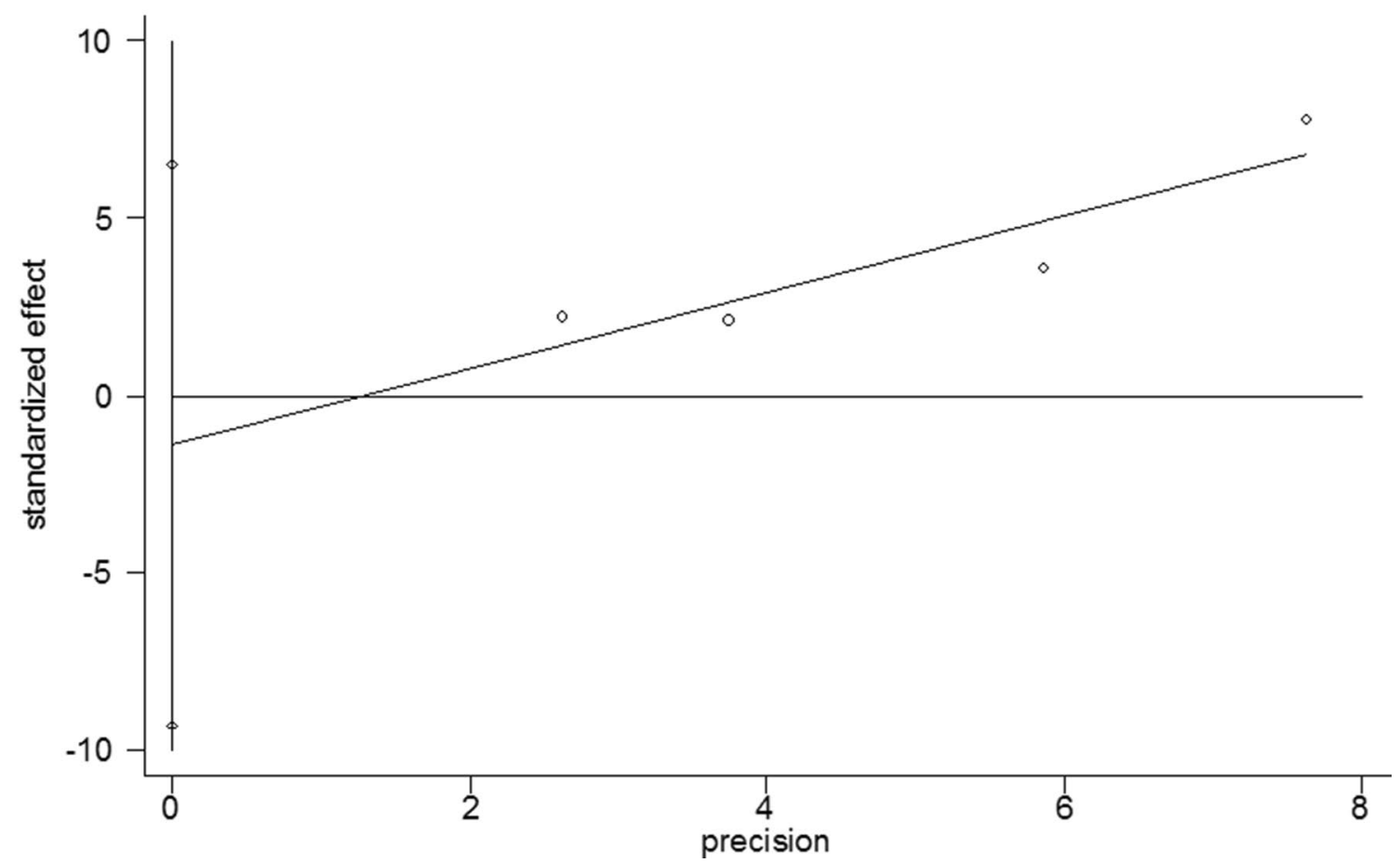

Fig. 7 Plots for publication bias test in meta-analysis for recurrence-free survival. a Begg's funnel plot; $\mathbf{b}$ Egger's publication bias plot 


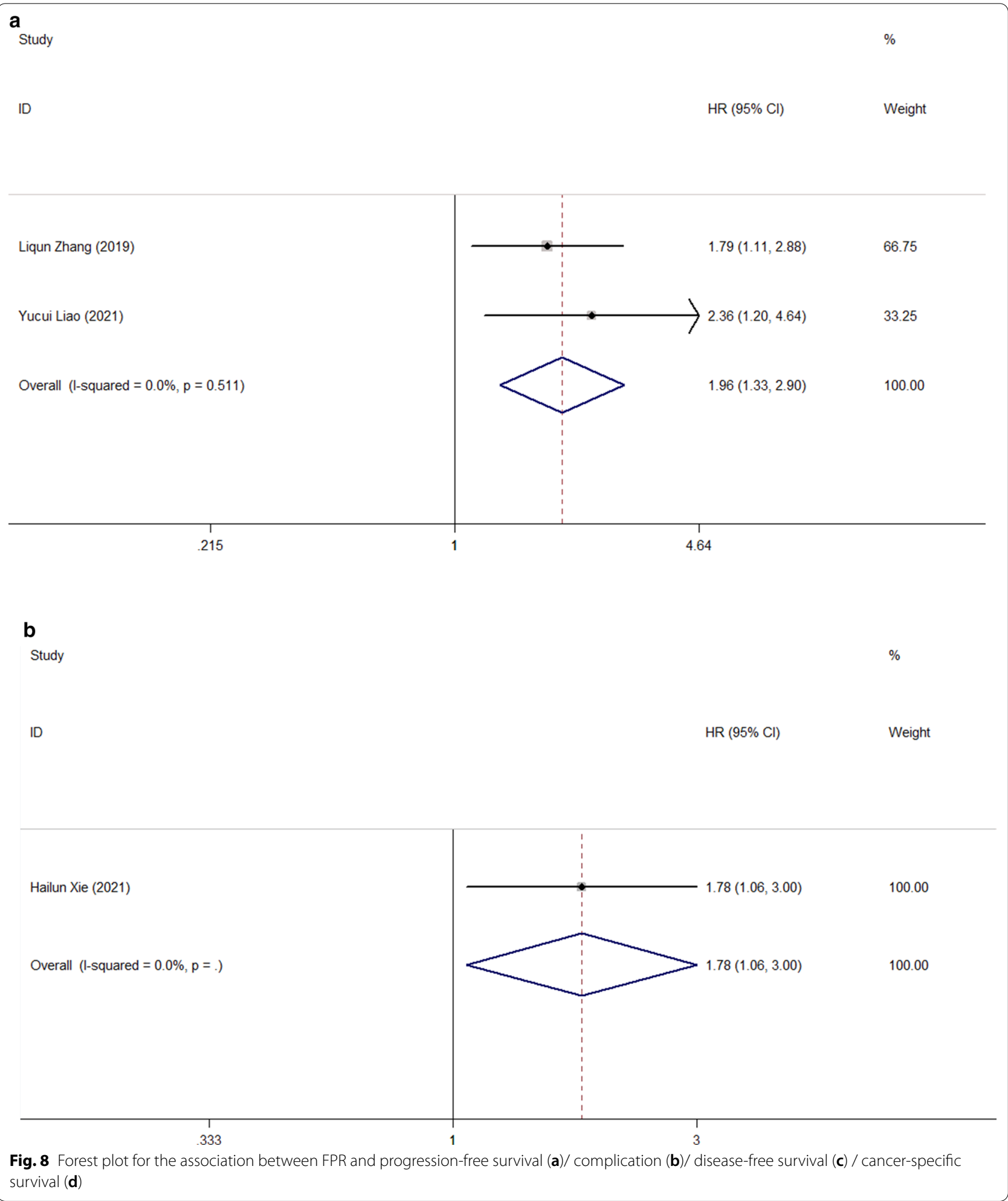




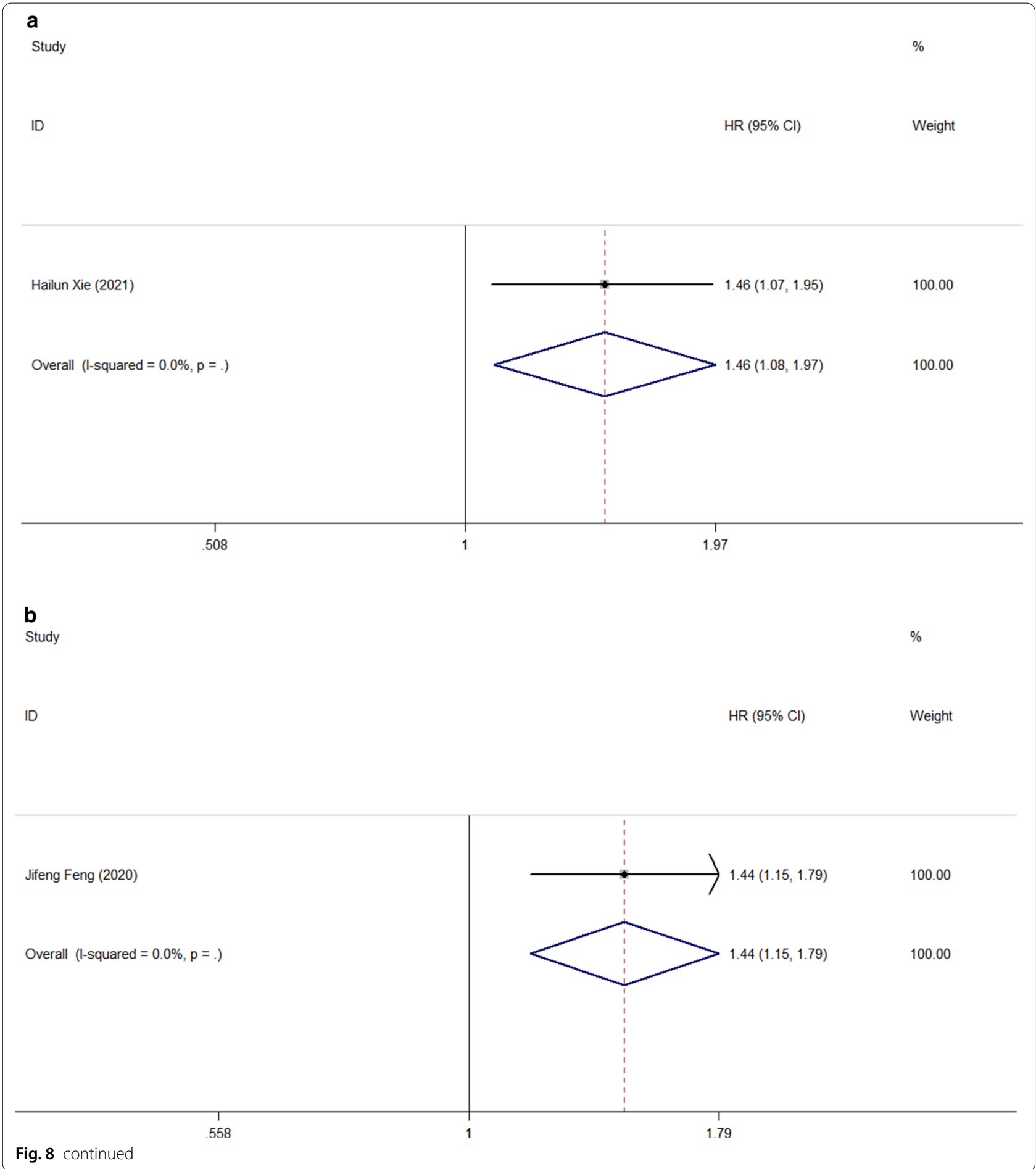

\section{Conclusion}

According to this meta-analysis, high FPR is significantly correlated with poor prognosis, which can be harnessed clinically as an indicator to predict the prognosis of patients with malignant tumors of the digestive system. However, large multicenter studies worldwide are still needed to substantiate our findings. 


\section{Abbreviations}

FPR: Fibrinogen to pre-albumin ratio; 95\% Cl: 95\% Confidence interval; OS: Overall survival; CSS: Cancer-specific survival; DFS: Disease-free survival; RFS: Recurrence-free survival; PFS: Progression-free survival.

\section{Acknowledgements}

We would like to thank the researchers and study participants for their contributions.

\section{Authors' contributions}

$\mathrm{BL}$ and $\mathrm{HD}$ designed this research; $\mathrm{ZZ}$ and $\mathrm{BT}$ performed the statistical analysis; $\mathrm{BL}$ and $\mathrm{HD}$ performed the data extraction, and drafted and revised the manuscript. All authors reviewed and approved the final manuscript. All authors read and approved the final manuscript.

\section{Funding}

This research was supported in part by Guangxi Natural Science Foundation for Key Program of Research \& Development (GuiKe AB21075003), Guangxi Natural Science Foundation for Guangdong-Guangxi United Program (2021GXNSFDA075014).

\section{Availability of data and materials}

Please contact author for data requests.

\section{Declarations}

\section{Ethics approval and consent to participate}

Not applicable.

\section{Consent for publication}

Not applicable.

\section{Competing interests}

The authors declare that there is no conflict of interest.

\section{Author details}

${ }^{1}$ Department of Hepatobiliary Surgery, The First Affiliated Hospital of Guangxi Medical University, No 6 Shuangyong Road, Nanning 530021, Guangxi, People's Republic of China. ${ }^{2}$ Department of Gastrointestinal Surgery, the First Affiliated Hospital of Guangxi Medical University, Nanning 530021, Guangxi, People's Republic of China. ${ }^{3}$ Department of Radiation Oncology, the First Affiliated Hospital of Guangxi Medical University, Nanning 530021, Guangxi, People's Republic of China.

Received: 26 September 2021 Accepted: 1 January 2022

Published online: 15 January 2022

\section{References}

1. Bray F, Ferlay J, Soerjomataram I, Siegel RL, Torre LA, Jemal A. Global cancer statistics 2018: GLOBOCAN estimates of incidence and mortality worldwide for 36 cancers in 185 countries. CA Cancer J Clin. 2018:68(6):394-424.

2. Lee SE, Lee JH, Ryu KW, Nam BH, Cho SJ, Lee JY, Kim CG, Choi IJ, Kook MC, Park SR, et al. Preoperative plasma fibrinogen level is a useful predictor of adjacent organ involvement in patients with advanced gastric cancer. J Gastric Cancer. 2012;12(2):81-7.

3. Pieters M, Ferreira M, de Maat MPM, Ricci C. Biomarker association with cardiovascular disease and mortality - the role of fibrinogen A report from the NHANES study. Thrombosis Res. 2021;198:182-9.

4. <The Role of Fibrinogen as an_Extracellular Matrix Protein.pdf>.

5. Sahni A, Khorana AA, Baggs RB, Peng H, Francis CW. FGF-2 binding to fibrin(ogen) is required for augmented angiogenesis. Blood. 2006;107(1):126-31.

6. Ji R, Ren Q, Bai S, Wang Y, Zhou Y. Prognostic significance of pretreatment plasma fibrinogen level in patients with digestive system tumors: a metaanalysis. Int J Biol Markers. 2018;33(3):254-65.

7. Zhang Y, Cao J, Deng Y, Huang Y, Li R, Lin G, Dong M, Huang Z. Pretreatment plasma fibrinogen level as a prognostic biomarker for patients with lung cancer. Clinics (Sao Paulo). 2020;75:e993.
8. Smith $\mathrm{SH}$. Using albumin and prealbumin to assess nutritional status. Nursing. 2017:47(4):65-6.

9. <Low Serum Albumin Correlates with Poor Survival in Gastric Cancer Patients.pdf>

10. Sun DW, An L, Lv GY. Albumin-fibrinogen ratio and fibrinogen-prealbumin ratio as promising prognostic markers for cancers: an updated meta-analysis. World J Surg Oncol. 2020;18(1):9.

11. Page MJ, McKenzie JE, Bossuyt PM, Boutron I, Hoffmann TC, Mulrow CD, Shamseer L, Tetzlaff JM, AkI EA, Brennan SE, et al. The PRISMA 2020 statement: an updated guideline for reporting systematic reviews. J Clin Epidemiol. 2021;134:178-89.

12. Zhang L, Zhang J, Wang Y, Dong Q, Piao H, Wang Q, Zhou Y, Ding Y. Potential prognostic factors for predicting the chemotherapeutic outcomes and prognosis of patients with metastatic colorectal cancer. J Clin Lab Anal. 2019;33(8):e22958

13. Zhang J, Li SQ, Liao Z, Jiang Y-h, Chen Q-G, Huang B, Liu J, Xu YM, Lin J,

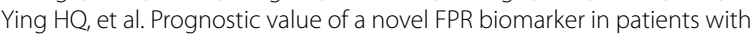
surgical stage II and III gastric cancer. Oncotarget. 2017;8:75195-205.

14. Sun F, Peng HX, Gao QF, Li SQ, Zhang J, Chen QG, Jiang YH, Zhang L, Wang XZ, Ying HQ. Preoperative circulating FPR and CCF score are promising biomarkers for predicting clinical outcome of stage II-III colorectal cancer patients. Cancer Manag Res. 2018;10:2151-61.

15. Du JH, Lu J. Circulating CEA-dNLR score predicts clinical outcome of metastatic gallbladder cancer patient. J Clin Lab Anal. 2019;33(2):e22684.

16. Zhang L, Chen QG, Li SQ, Zhang J, Min QH, Gao QF, Sun F, Jiang YH, Wang $X Z$, Ying $H Q$. Preoperative fibrinogen to prealbumin ratio as a novel predictor for clinical outcome of hepatocellular carcinoma. Fut Oncol. 2019;15(1):13-22

17. Tang S, Lin L, Cheng J, Zhao J, Xuan Q, Shao J, Zhou Y, Zhang Y. The prognostic value of preoperative fibrinogen-to-prealbumin ratio and a novel FFC score in patients with resectable gastric cancer. BMC Cancer. 2020;20(1):382.

18. Feng JF, Wang $L$, Jiang $Y H$, Yang $X$. A novel prognostic index in patients with resectable esophageal squamous cell carcinoma: fibrinogen/prealbumin ratio. Rev Invest Clin. 2020;72(1):46-54.

19. Liao YC, Fu M, Wang XF, Cheng XX. Combined fibrinogen-to-pre-albumin ratio and carbohydrate antigen 19-9 score is a promising metric to predict progression of metastatic colorectal mucinous adenocarcinoma. Clin Lab Anal. 2021;35(5):e23757.

20. Hailun X, Huang S, Yuan G, Tang S, Gan J. Prognostic significance of preoperative fibrinogen-to-prealbumin ratio in patients with stage I-III colorectal cancer undergoing surgical resection: a retrospective cohort study. Biomed Res Int. 2021;2021:3905353.

21. 周航亮, 陈鲜宝, 崔莹珊, 等. FPR在 $\mid$ | || 期结直肠癌患者术后辅助化疗 疗效判断和预后评估中的价值[J]. 检验医学, 2020(10). doi: https://doi. org/10.3969/j.issn.1673-8640.2020.10.012.

22. Chen QG, Zhang L, Sun F, Li SQ, You XH, Jiang YH, Yang WM, Zhong QH, Wang $X Z$, Ying HQ. Elevated FPR confers to radiochemoresistance and predicts clinical efficacy and outcome of metastatic colorectal cancer patients. Aging. 2019;11(6):1716-32.

23. Ying HQ, Liao YC, Sun F, Peng HX, Cheng XX. The role of cancer-elicited inflammatory biomarkers in predicting early recurrence within stage II-III colorectal cancer patients after curable resection. J Inflamm Res. 2021;14:115-29.

24. Liao YC, Ying HQ, Huang Y, Luo YR, Xiong CF, Nie RW, Li XJ, Cheng XX Role of chronic inflammatory ratios in predicting recurrence of resected patients with stage I-III mucinous colorectal adenocarcinoma. Cancer Manag Res. 2021;13:3455-64.

25. Lu J, Xu BB, Zheng ZF, Xie JW, Wang JB, Lin JX, Chen QY, Cao LL, Lin M, $\mathrm{Tu} \mathrm{RH}$, et al. CRP/prealbumin, a novel inflammatory index for predicting recurrence after radical resection in gastric cancer patients: post hoc analysis of a randomized phase III trial. Gastric Cancer. 2019;22(3):536-45.

26. Li W, Tang Y, Song Y, Chen SH, Sisliyan N, Ni M, Zhang H, Zeng Q, Hou B, Xie $X$, et al. Prognostic role of pretreatment plasma D-dimer in patients with solid tumors: a systematic review and meta-analysis. Cell Physiol Biochem. 2018:45(4):1663-76.

27. Darzi AJ, Karam SG, Charide R, Etxeandia-Ikobaltzeta I, Cushman M, Gould MK, Mbuagbaw L, Spencer FA, Spyropoulos AC, Streiff MB, et al. Prognostic factors for VTE and bleeding in hospitalized medical patients: a systematic review and meta-analysis. Blood. 2020;135(20):1788-810. 
28. Perisanidis C, Psyrri A, Cohen EE, Engelmann J, Heinze G, Perisanidis B, Stift A, Filipits M, Kornek G, Nkenke E. Prognostic role of pretreatment plasma fibrinogen in patients with solid tumors: a systematic review and metaanalysis. Cancer Treat Rev. 2015;41(10):960-70.

29. van Holten TC, Waanders LF, de Groot PG, Vissers J, Hoefer IE, Pasterkamp G, Prins MW, Roest M. Circulating biomarkers for predicting cardiovascular disease risk; a systematic review and comprehensive overview of meta-analyses. PLoS ONE. 2013;8(4):e62080.

30. Zhang Z, Zhang R, Qi J, Miao W, Fang K, Ruan C, Wu D, Han Y. The prognostic value of plasma fibrinogen level in patients with acute myeloid leukemia: a systematic review and meta-analysis. Leuk Lymphoma. 2020;61(11):2682-91.

31. Cai W, Kong W, Dong B, Zhang J, Chen Y, Xue W, Huang Y, Zhou L, Huang J. Pretreatment serum prealbumin as an independent prognostic indicator in patients with metastatic renal cell carcinoma using tyrosine kinase inhibitors as first-line target therapy. Clin Genitourin Cancer. 2017;15(3):e437-46.

32. Huang W, Wang $\mathrm{S}$, Zhang $\mathrm{H}$, Zhang B, Wang C. Prognostic significance of combined fibrinogen concentration and neutrophil-to-lymphocyte ratio in patients with resectable non-small cell lung cancer. Cancer Biol Med. 2018;15(1):88-96.

33. 李然天, 孙紫千,王红兵. 纤维蛋白原与前白蛋白比値对中晚期非小细 胞肺癌预后作用的研究[J]. 临床肿瘤学杂志,2019(3). DOl:https://doi. org/10.3969/j.issn.1009-0460.2019.03.009.

34. 吴佳成,翟宝茜,姜力. 术前纤维蛋白原与前白蛋白比値预测非肌层浸 润性膀胱癌患者行经尿道膀胱肿瘤电切术预后临床价值[J]. 临床军 医杂志,2020(12). DOl:https://doi.org/10.16680/j.1671-3826.2020.12.36.

35. Chen C, Liu Y, Han P, Cui B. Research progress of preoperative FPR, FAR or AFR in patients with colorectal cancer. Cancer Manag Res. 2021;13:1791-801.

36. Song M, Garrett WS, Chan AT. Nutrients, foods, and colorectal cancer prevention. Gastroenterology. 2015;148(6):1244-1260 e1216.

37. Gabay C, Kushner I. Acute-phase proteins and other systemic responses to inflammation. N Engl J Med. 1999;340(6):448-54.

38. Steinbrecher KA, Horowitz NA, Blevins EA, Barney KA, Shaw MA, HarmelLaws E, Finkelman FD, Flick MJ, Pinkerton MD, Talmage KE, et al. Colitisassociated cancer is dependent on the interplay between the hemostatic and inflammatory systems and supported by integrin alpha(M)beta(2) engagement of fibrinogen. Cancer Res. 2010;70(7):2634-43.

39. Jensen T, Kierulf P, Sandset PM, Klingenberg O, Joo GB, Godal HC, Skjonsberg $\mathrm{OH}$. Fibrinogen and fibrin induce synthesis of proinflammatory cytokines from isolated peripheral blood mononuclear cells. Thromb Haemost. 2007;97(5):822-9.

40. Kaneider NC, Mosheimer B, Gunther A, Feistritzer C, Wiedermann CJ. Enhancement of fibrinogen-triggered pro-coagulant activation of monocytes in vitro by matrix metalloproteinase-9. Thromb J. 2010;8(1):2.

41. Desgrosellier JS, Cheresh DA. Integrins in cancer: biological implications and therapeutic opportunities. Nat Rev Cancer. 2010;10(1):9-22.

42. Zheng S, Shen J, Jiao Y, Liu Y, Zhang C, Wei M, Hao S, Zeng X. Platelets and fibrinogen facilitate each other in protecting tumor cells from natural killer cytotoxicity. Cancer Sci. 2009;100(5):859-65.

43. Palumbo JS, Talmage KE, Massari JV, La Jeunesse CM, Flick MJ, Kombrinck KW, Jirouskova M, Degen JL. Platelets and fibrin(ogen) increase metastatic potential by impeding natural killer cell-mediated elimination of tumor cells. Blood. 2005;105(1):178-85.

44. Roche Y, Pasquier D, Rambeaud J-J, Seigneurin D, Duperray A. Fibrinogen mediates bladder cancer cell migration in an ICAM-1-dependent pathway. Thromb Haemost. 2003;89(6):1089-97.

45. Palumbo JS, Kombrinck KW, Drew AF, Grimes TS, Kiser JH, Degen JL, Bugge $\mathrm{TH}$. Fibrinogen is an important determinant of the metastatic potential of circulating tumor cells. Blood. 2000;96(10):3302-9.

46. Marcelli D, Wabel P, Wieskotten S, Ciotola A, Grassmann A, Di Benedetto A, Canaud B. Physical methods for evaluating the nutrition status of hemodialysis patients. J Nephrol. 2015;28(5):523-30.

\section{Publisher's Note}

Springer Nature remains neutral with regard to jurisdictional claims in published maps and institutional affiliations.

Ready to submit your research? Choose BMC and benefit from:

- fast, convenient online submission

- thorough peer review by experienced researchers in your field

- rapid publication on acceptance

- support for research data, including large and complex data types

- gold Open Access which fosters wider collaboration and increased citations

- maximum visibility for your research: over 100M website views per year

At BMC, research is always in progress.

Learn more biomedcentral.com/submissions 